\title{
Spectrum of Nonneoplastic Lesions of Uterine Cervix in Uttarakhand
}

\section{ABSTRACT}

Introduction: Cervical lesions are more frequent and commonly encountered day today problem of gynaecological lesions in women. Cervical lesions, both neoplastic and non-neoplastic, are prime reason for morbidity and mortality in women.

Aim: The study was conducted to explore various nonneoplastic lesions of cervix at government hospital, Uttarakhand.

Materials and Methods: 315 non-neoplastic cervices were analyzed either from hysterectomy or biopsy specimens. These cervices were subjected to detailed gross and microscopic examination and further categorized into various non-neoplastic lesions.

Results: Of all the non-neoplastic lesions, a total of 291(92.38\%) of cervical specimens shows cervicitis. Chronic nonspecific cervicitis was the most commonly encountered lesions in $85.56 \%$ of all inflammatory lesions. However, acute or chronic cervicitis was found in only 18 cases $(6.185 \%)$ and tuberculosis cervicitis was encountered in only one patient $(0.343 \% \%)$. Cervicitis with koilocytic changes in HPV is present in $(7.90 \%)$. The peak age for non-neoplastic lesion was $40-60$ years. Nabothian cyst (31.11\%) and Squamous metaplasia (14.92\%) were another common lesions present. Endocervical hyperplasia and endocervical polyp present in only $1.26 \%$ and $2.22 \%$ cases. Among the ectocervical changes, hyperplasia were the commonest and found in $12.06 \%$.

Conclusion: Histopathology is the best method to detect cervical lesions. Further, large scale multi-factorial studies are essential in this field. Routine Pap smear test in reproductive age group is as way of reducing the occurrence of carcinoma of the cervix in our setup with existing resources.

\section{INTRODUCTION}

Gynecological specimens forms the major proportion of tissue biopsy in most histopathological departments [1]. Sexually active women are more prone for cervical disease $[1,2]$. The lesions include predominantly inflammatory and some tumor likes non neoplastic lesions [3]. Different varieties of non neoplastic lesion, occuring in uterine cervix, are often misinterpreted. Therefore, the histopathology is the best diagnostic tool for the diagnosis of non neoplastic cervical lesions [4].The inflammatory lesions of cervix are acute cervicitis, chronic cervicitis and chronic granulomatous cervicitis [5]. The chronic cervicitis is the commonest lesion. The term "chronic" in chronic cervicitis implies more for the duration of symptoms. Chronic Cervicitis is characterized histologicaly by the infiltration of heavy mixed chronic inflammatory cells including lymphocytes, plasma cells, histiocytes and occasional neutrophills. Spongiosis, ulceration, inflammatory necrosis and erythma are the various histological presentation of acute cervicitis [6].
Acute and chronic cervicitis can be infective and non infective. Non infective cervicitis is chemical in nature. Infective cervicitis can be bacterial, viral, protozoal and fungal. Mycobacterium tuberculosis is a leading cause of chronic granulomatous cervicitis [7]. Primary tuberculosis of cervix is rare, it usually secondary to disseminated tuberculosis. Hypertrophy and ulcerative lesions are the most common presentation of tubercular cervicitis and can simulate the as carcinoma cervix on gross [8]. Human papilloma viruses and Herpes simplex virus is common causal agent for viral cervicitis and are strongly associated with condyloma acuminatum, pre invasive cervical intraepithelial neoplasia and cervical carcinoma [9]. Non neoplastic tumors like lesions of cervix are endocervical hyperplasia, endocervical polyp, nabothian cyst and endometriosis etc.,[10-12]. However, these lesions are mostly seen in association with cervicitis as well. These tumor like conditions are often mistaken as neoplastic lesion. This can result in inappropriate and inadequate treatment of the patient. 
The present study was undertaken with the aim to establish the prevalence and histopathological patterns of nonneoplastic cervical lesions in Garhwal region of Uttarakhand to provide base line data for treatment of these lesion and further research.

\section{MATERIALS AND METHODS}

A retrospective histopathological analysis of 315 Nonneoplastic lesions of uterine cervix was undertaken in the department of pathology over a period from March 2011 to February 2015 at Government Medical College SricotSrinagar, Uttarakhand.

The material for the study consists of both cervical punch biopsy and cervix from hysterectomy specimens. All the slides and blocks from Pathology Department, examined in detail. Sections were cut from paraffin embedded blocks and stained with routine haematoxiline and eosin. Zeil-nelson staining was done to rule out tubercular lesion in required cases. All Clinical data regarding age, parity and clinical features was collected from histopathology request forms and medical records. Non-neoplastic lesions of uterine cervix studied in detail for inflammatory and epithelial changes.

\section{RESULTS}

A total of 315 non-neoplastic lesions from cervical specimen either from hysterectomy or cervical biopsy were analysed in the pathology department during the study period.

The age of patient in this study were ranges from 20-75 years with peak age incidence of 40 to 60 years. Multiparty was seen in $80 \%$ of cases. White discharge per vagina was seen in (33.65\%), mass per vagina in (25.39\%), irregular menses and excessive bleeding per vagina (25.71\%), pain in abdomen in (6.98\%) and post coital bleeding in(8.25\%) patients [Table/Fig-1].

Of the 315 non-neoplastic cervical specimen, 279 were from hysterectomy specimen and 56 from the cervical biopsy either punch, cone biopsy or endocervical curettage.

Of 279 cervical hysterectomies, the cervix appeared normal in $67.74 \%$, hypertrophied in $20.07 \%$, epidermidised in $11.47 \%$ and ulcerated in $0.72 \%$ [Table/Fig-2]. On cutting, cut surface was unremarkable in $46.59 \%$, Nabothian follicular cyst were seen in $32.97 \%$.cases. Polyp and erosion were seen in $1.08 \%$ and $19.35 \%$ cases respectively [Table/Fig-3].

\begin{tabular}{|l|c|c|}
\hline Clinical symptoms & Number & Percentage \\
\hline White discharge & 106 & $33.65 \%$ \\
\hline Mass & 80 & $25.40 \%$ \\
\hline Irregular / excessive bleeding per vagina & 81 & $25.71 \%$ \\
\hline Pain abdomen & 22 & $6.98 \%$ \\
\hline Post coital bleeding & 26 & $8.25 \%$ \\
\hline \\
[Table/Fig-1]: Clinical sign and symptoms in non-neoplastics \\
lesions.
\end{tabular}

\begin{tabular}{|l|c|c|}
\hline External surface & Number & Percentage \\
\hline Normal cervix & 189 & $67.74 \%$ \\
\hline Hypertrophied & 56 & $20.07 \%$ \\
\hline Epidermidised & 32 & $11.47 \%$ \\
\hline Ulcerated & 02 & $0.72 \%$ \\
\hline Total number & 279 & $100 \%$ \\
\hline
\end{tabular}

\begin{tabular}{|l|c|c|}
\hline Cut surface & Number & Percentage \\
\hline Unremarkable & 130 & $46.59 \%$ \\
\hline Nabothian follicular cyst & 92 & $32.97 \%$ \\
\hline Polyp & 03 & $1.08 \%$ \\
\hline Erosion & 54 & $19.35 \%$ \\
\hline
\end{tabular}

[Table/Fig-3]: Gross features of cervix on cut surface.
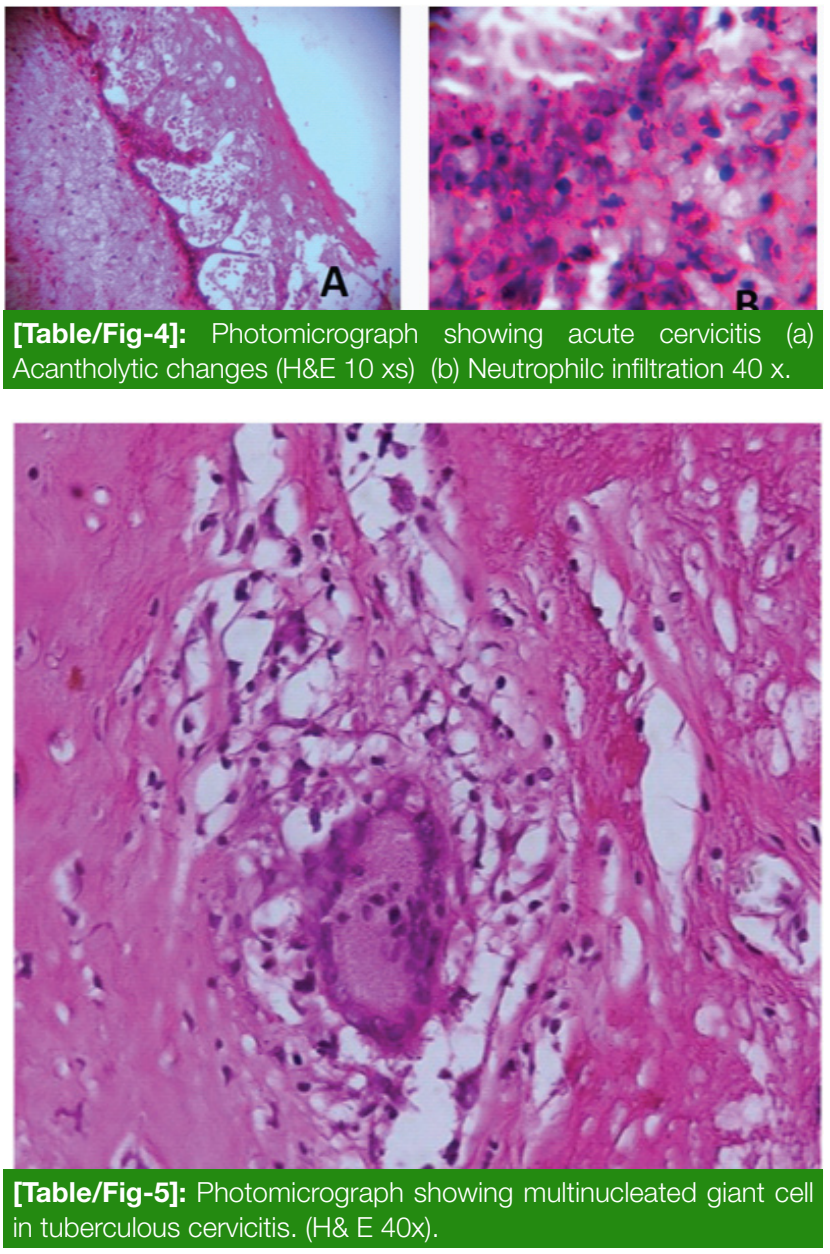

On microscopic examination of 315 non-neoplastic cases, inflammatory lesions accounted in 291(92.38\%) and tumor like lesion in 24 cases (7.62\%). Among the inflammatory lesions chronic nonspecific cervicitis was the most common lesion constituting (85.56\%) of cases. Acute cervicitis [Table/ Fig-4] was seen in (6.185\%) and a single case of tuberculous National Journal of Laboratory Medicine. 2016 Apr, Vol 5(2): 39-43 
cervicitis (0.343\%) [Table/Fig-5] was present. Human papilloma virus cervicitis with koilocytic changes accounted for (7.90\%). [Table/Fig-6].

Squamous metaplasia [Table/Fig-7] seen in (14.9\%) and nabothian cyst seen in (31.11\%) [Table/Fig-8a] cases of all non-neoplastic lesions. Endocervical hyperplasia and polyp seen in (1.26\%) and (2.22\%) respectively of all non-neoplastic lesions. [Table/Fig-8b] Ectocervical hyperplasia seen in $12.06 \%$ cases. Of all non-neoplastic lesions exocytosis, suprabasal bullae seen in one case each [Table/Fig-9].
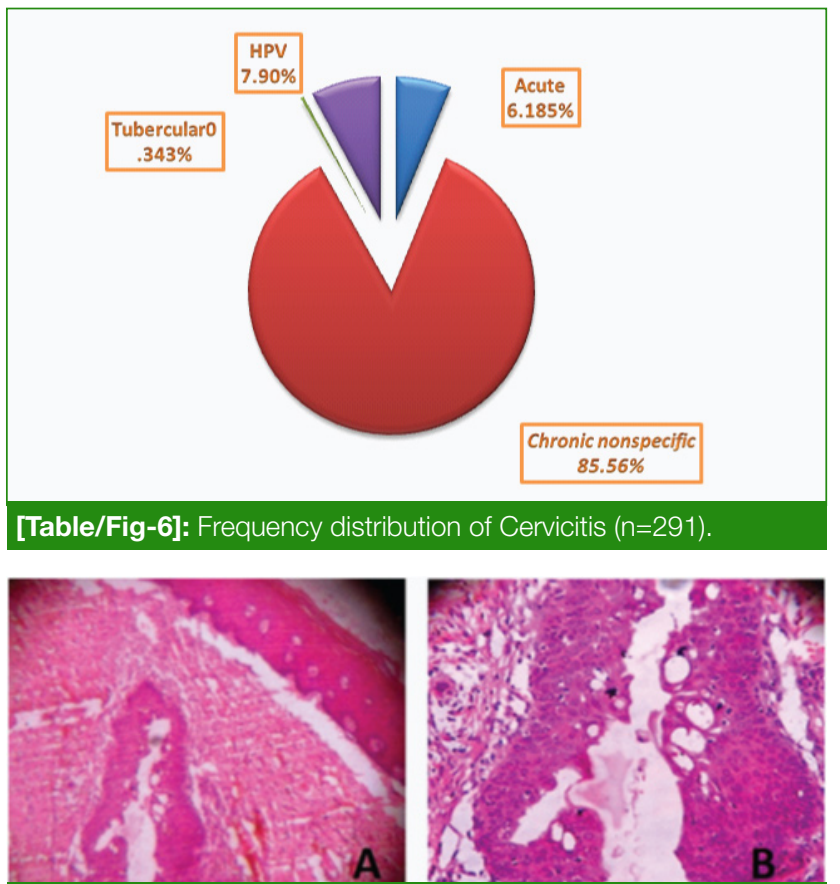

[Table/Fig-7]: Photomicrograph showing squamous metaplasia in cervix (a) H\&E 10x (b) H\& E 40x.

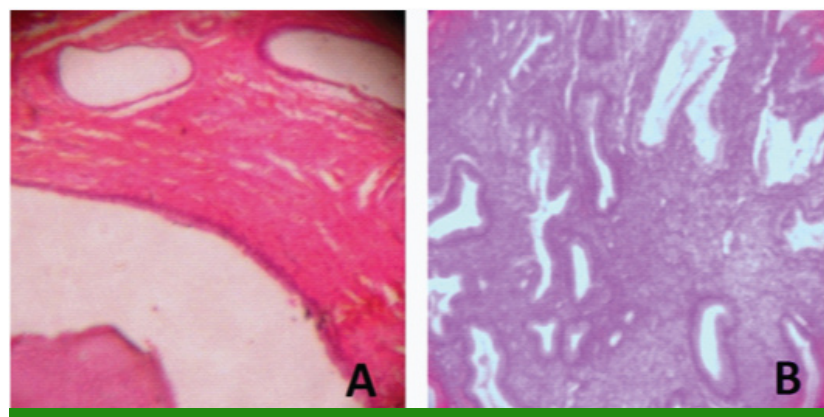

[Table/Fig-8]: Photomicrograph showing a) Numerous nabothian cyst (H\&E 10x). b) Endocervical polyp. (H\&E 10X).

\section{DISCUSSION}

Incidence of carcinoma cervix has declined in developed countries, but cervix is still the one most common histopathological specimen in pathology department [13]. The diagnosis of cervical lesions is grossly neglected [14].

\begin{tabular}{|l|c|c|}
\hline Histological finding & Number & $\begin{array}{c}\text { Percentage among } \\
\text { non-neoplastic cervix }\end{array}$ \\
\hline Squamous metaplasia & 47 & $14.92 \%$ \\
\hline Nabothian cyst & 98 & $31.11 \%$ \\
\hline Endocervical polyp & 7 & $2.22 \%$ \\
\hline Endocervical hyperplasia & 4 & $1.26 \%$ \\
\hline Koilocytosis & 23 & $7.30 \%$ \\
\hline Ectocervical hyperplasia & 38 & $12.06 \%$ \\
\hline Cervical Prolapse & 2 & $0.634 \%$ \\
\hline Suprabasal bulla & 1 & $0.317 \%$ \\
\hline Granulation tissue & 1 & $0.317 \%$ \\
[Table/Fig-9]: The numerous histological changes encountered in \\
cervix.
\end{tabular}

The peak age of non-neoplastic lesions of cervix in our study was 40 to 60 years and account for (49.4\%). These findings are consistent with the study of FN et al., (33.7\%) and lle-life et (34.7\%) [15]. In the present study, the cervix on external surface looked predominantly unremarkable (67.74\%). The findings are consistent with previous findings which shows that hysterectomy specimens in non-neoplastic lesions of the cervix do not exhibit any major morphologic variations $[13,14]$.

In present study, inflammation of the cervix was found in 92.38\% of all non-neoplastic cervices. Findings of our study are similar to the observations made by Howard et al., (98\% of 400 specimens) and Hawkins and Bourne (80\%) [16]. Omoniyi et al., in their study reported incidence of chronic nonspecific cervictis $82 \%$ of all non -neoplastic lesions [3]. In our study, we observed $85.56 \%$ of chronic nonspecific cervicitis, which was similar to previous study. Sexual intercourse, conception, pregnancy, delivery and postpartum are considered as main causal factor to cervicitis through sexually transmitted disease and urinary tract infection. Mycoplasma genitalium, Neisseria gonorrhoeae, Chlamydia trachomatis, and Staphylococcus aureus in female of developing countries are main sexually transmitted infection result in cervicitis [17-19]. A Nigerian study shown $10.5 \%$ chronic cervicitis in adolescent female who are sexually active [3].

Tuberculosis and shistosomiasis are most common form of chronic granulomatous cervicitis, commonly seen in tropical areas. The incidence of cervical tuberculosis in worldwide population is very rare and account for 0.1 to $0.6 \%$, more commonly affects the fallopian tubes, the corpus, ovary and rarely cervix [20]. In this study only one case $(0.343 \%)$ of tubercular cervicitis is reported, and thus the findings are concurred with the previous study.

HPV cervicitis is particularly a high risk type cervicitis that results in cervical cancer in worldwide population. Prevalence of HPV cervicitis reported in Argentina (15\%), Ibadan 
(26.3\%) and Uganda 17\% respectively $[21,22]$. Koilocytosis is considered as the histological hallmark of papilloma virus infection. In present study, koilocytosis was encountered in 23 cases (7.90\%), among all non-neoplastics lesions. Our findings correlate with the findings of Armadas Naik [23]. It has been proved by various studies that association of HPV infection (koilocytosis), HIV infection and lower CD4 counts have predisposed to cervical intraepithelial carcinoma and malignancy $[24,25]$. The specificity of diagnosis of HPV has increased by technique like polymerase chain reaction, HPV genotyping, in situ hybridization and molecular studies. Therefore the timely detection of HPV cervicitis reduces the frequency of malignancies in such HIV positive patients [26]. HPV vaccine plays a key role in the prevention of cervical cancer in developing countries [27].

The patients of acute cervicitis usually do not required cervical biopsy because most they are medically treated because of acute discomfort and purulent cervical discharge. Olutoyin et al., in their study received only $2 \%$ of acute cervicitis $[3,26]$. In our study acute cervitis was present in $6.185 \%$ of cases and consistent with findings of previous study.

Squamous metaplasia in cervix is a physiological change in female during puberty, reproductive years, menopause and very commonly encountered under microscopic examination. The proper recognition of squamous metaplasia on histopathology can avoid an over diagnosis of CIN (cervical intraepithelial neoplasia) [28-30]. In the present study squamous metaplasia seen in $14.9 \%$ and the findings are agreed with the previous study.

Of all the non neoplastic lesions endocervical hyperplasia was seen in $1.26 \%$ and endocervical polyp in $2.22 \%$ cases. These findings are similar to findings of study done by Pallipady et al., .Where endocervical hyperplasia seen in $4.3 \%$ and polyp in $1.87 \%$ of non-neoplastic cervical biopsy [5, 31]. The endocervical polyp may present as irregular vaginal bleeding or spotting which arouses suspicion of some more serious lesions [32].

In our study we observed only single case of suprabasal bulla with acantholytic squamous cells. The reason for this can be the rarity of the lesions and findings are consistent with findings of Pallipady et al., (supra basal bulla $0.19 \%$ and exocytosis 3.54\%) [5].

We could not perform Elisa, HPV serology and immunohistochemistry in this study due to their nonavilability in our setup and high cost. The effectiveness of Pap ( Papanicolaou-stained smear) test in detecting cervical precancers, easy accessibility to cervix by colposcopy and biopsy are the best tool for early detection and eradication of preinvasive lesions, some of it may progressed to cancer if not diagnosed and treated timely [33].

\section{CONCLUSION}

Histopathology is the best method to detect cervical lesions. Further large scale multi-factorial studies are essential in this field. Routine Pap smear test as screening is recommended as a way of reducing the occurrence of carcinoma of the cervix in our setup with existing resources.

\section{REFERENCES}

[1] Sebanti G, Rekah D, Sibani S. A profile of adolescent girls with gynaecological problems. Obstet Gynaecol India. 2005;55(4): 353-55.

[2] Workowski KA, Bolan GA. Sexually transmitted diseases treatment guidelines, 2015. Centers for Disease Control and Prevention. MMWR Recomm Rep. 2015;64(RR-03):1-137.

[3] Olutoyin G. Omoniyi-Esan OG, Osasan SA, Ojo OS. Nonneoplastic diseases of the cervix in Nigerians: A histopathological study. Afr Health Sci. 2006;6:76-80.

[4] Mostafa MG, Srivannuboon s, Rachanawutanon M. Accuracy of cytological findings in abnormal cervical smears by cytohistologic comparison. Indian J Pathol Microbiol. 2000; 43(10): 23-29.

[5] Pallipady A, Illanthody S, Vaidya R, Ahmed Z, Suvarna R, Metkar $G$ et al. A Clinico-Morphological spectrum of the Non-neoplastic lesions of the uterine cervix at AJ Hospital Mangalore. Journal of Clinical and Diagnostic Research. 2011; 5: 546-50.

[6] Konje JC, Ogunniyi JO. Otolorin EO. Odusoga OL et al. Cervical cancer screening at Ibadan. Eur. J. Gynaecol Oncol.1991; 12(1):55-56.

[7] Gupta R, Dey P, Jain V, Gupta N. Cervical tuberculosis detection in Papanicolaou-stained smear: case report with review of literature. Diagn Cytopathol. 2009 ;37(8):592-95.

[8] Sachan R, Gupta P, Patel ML, Verma A, Maurya M. Cervical tuberculosis masquerading as cancer cervix: a report of three cases. Indian J Tuberc. 2013 ; 60(1):46-49.

[9] Feng YK, Peng Y, Zhu L, Niu XY. Relationship of human Papillomavirus subtypes and multiple infections with different cervical precancerous diseases in Sichuan Province. Sichuan Da Xue Xue Bao Yi Xue Ban. 2015; 46(3):422-25, 462.

[10] Terada $\mathrm{T}$; Large endocervical polyp with cartilaginous and osseous metaplasia: a hitherto unreported entity. Int J Gynecol Pathol. 2009; 28(1):98-100.

[11] Vural F, Sanverdi I, Coskun AD, Kusgöz A, Temel O. Large nabothian cyst obstructing labour passage. J Clin Diagn Res. 2015;9(10):QD06-7.

[12] Phadnis SV, Doshi JS, Ogunnaike O, Coady A, Padwick M, Sanusi FA. Cervical endometriosis: a diagnostic and management dilemma. Arch Gynecol Obstet. 2005 ;272(4):289-93

[13] Wright Ct, Ferenczy A. Benign diseases of the cervix. In: Kurman RT, editor. Blaustein's pathology of female genital tract. $5^{\text {th }}$ ed. New Delhi: Springer Verlag; 2002 .p.225-252.

[14] Craig P, Lowe D. Non-neoplastic lesions of the cervix. In: Fox $H$, Well M, editors. Haines and Taylor Obstetrical and Gynaecological pathology $5^{\text {th }}$ ed. Edinburgh: Churchill Livingstone; 2003 .p.273- 96.

[15] Nwachokor F N, Forae G C. Morphological spectrum of nonneoplastic lesions of the uterine cervix in Warri, South-South, Nigeria. Niger J Clin Pract. 2013;16:429-32.

[16] N Padubidri VG, Daftary SW, editors Howkins and Bourne Shaw's Text Book of Gynaecology. New Delhi: Chruchill Livingstone; 2004.

[17] Dehon PM, McGowin CL. Mycoplasma genitalium infection is associated with microscopic signs of cervical inflammation in liquid cytology specimens. J Clin Microbiol. 2014; 52(7):2398405. 
[18] Lewis ME, Belland RJ, Abdel Rahman YM, Beatty WL, Aiyar AA et al. Morphologic and molecular evaluation of Chlamydia trachomatis growth in human endocervix reveals distinct growth patterns. Front Cell Infect Microbiol. 2014;4:71

[19] Efosa OB, Uwadiegwu AP. Cytopathological examination and epidemiological study of cervicitis in commercial sex workers (Csws) in Coal City (Enugu), Nigeria. Ethiop J Health Sci. 2015 ;25(3):225-30.

[20] Ozumba BC, Nzegwu MA, Anyikam A. Histological patterns of gynaecological lesions in Enugu, Nigeria. A five year review. Adv Biores. 2011;2:132-36

[21] Matos E, Lotia D, Amestoy G, Herrera L, Prince MA, Moreno $J$, et al. Prevalence of human papillomavirus infection among women in Concordia, Argentina: A population-based study. Sex Transm Dis. 2003;30:593-99.

[22] Thomas JO. Prevalence of HPV in Ibadan. Br J Cancer. 2004; 90:638-45.

[23] Naik R, Pai RM, Baliga PB, Nayak KS, et al. Mast cell profile in uterine cervix. Indian J Pathol Microbiol. 2004; 47(2): 178-80.

[24] Yang EJ, Quick MC, et al. Microanatomy of the cervical and anorectal squamocolumnar junctions: a proposed model for anatomical differences in HPV-related cancer risk. Mod Pathol. 2015;28(7):994-1000.

[25] Yamada R, Sasagawa T, Kirumbi LW, et al. Inoue Human papillomavirus infection and cervical abnormalities in Nairobi, Kenya, an area with a high prevalence of human immunodeficiency virus infection. J Med Virol. 2008; 80(5):847-55.

[26] Gupta V, Tandon A, Nanda A, Sharma A, Bansal N, Mini Singhal; Correlation between Cytology, HPV -DNA test and colposcopy in evaluation of cervical intraepithelial lesions. JSAFOMS. 2014;2(2): 71-74
[27] Ugwu EO, Obi SN, Ezechukwu PC, Okafor II, Ugwu AO. Acceptability of Human papilloma virus vaccine and cervical screening among female health worker in Enugu, Southeast Nigeria. Niger J Clin Pract. 2013; 16:249-52.

[28] Skapa P, Robova H, Rob L, Zamecnik J. p16(INK4a) immunoprofiles of squamous lesions of the uterine cerviximplications for the reclassification of atypical immature squamous metaplasia. Pathol Oncol Res. 2013;19(4):707-14.

[29] Koay MH, Crook M, Stewart CJ. Fascin expression in cervical normal squamous epithelium, cervical intraepithelial neoplasia, and superficially invasive (stage IA1) squamous carcinoma of the cervix. Pathology. 2014; 46(5):433-38.

[30] Redman R, Rufforny I, Liu C, Wilkinson EJ, Massoll NA. The utility of p16 (Ink4a) in discriminating between cervical intraepithelial neoplasia 1 and nonneoplasticequivocal lesions of the cervix. Arch Pathol Lab Med. 2008; 132(5):795-99.

[31] Younis MT, Iram S, Anwar B, Ewies AA. Women with asymptomatic cervical polyps may not need to see a gynaecologist or have them removed: an observational retrospective study of 1126 cases. Eur J Obstet Gynecol Reprod Biol. 2010 ; 150(2):190-94.

[32] Loureiro J, Oliva E. The spectrum of cervical glandular neoplasia and issues in differential diagnosis. Arch Pathol Lab Med. 2014; 138(4):453-83.

[33] Barut MU, Kale A, Kuyumcuo lu U, Bozkurt M, et al. Analysis of Sensitivity, Specificity, and Positive and Negative Predictive Values of Smear and Colposcopy in Diagnosis of Premalignant and Malignant Cervical Lesions. Med Sci Monit. 2015;21:386067.

\section{AUTHOR(S):}

1. Dr. Deepa Hatwal

2. Dr. Neha Batra

3. Dr. Arvind Kumar

4. Dr. Sheela Chaudhari

5. Dr. Sachan Bhatt

\section{PARTICULARS OF CONTRIBUTORS:}

1. Associate Professor, Department of Pathology, Veer, Chandra, Singh, Garhwali, Governtment, Medical College and Research Institute, Sricot Srinagar Garhwal, India.

2. Assistant Professor, Department of Pathology, Veer, Chandra, Singh, Garhwali, Governtment, Medical College and Research Institute, Sricot Srinagar Garhwal, India.

3. Assistant Professor, Department of Pathology, Veer, Chandra, Singh, Garhwali, Governtment, Medical College and Research Institute, Sricot Srinagar Garhwal, India.
4. Associate Professor, Department of Pathology, Veer, Chandra, Singh, Garhwali, Governtment, Medical College and Research Institute, Sricot Srinagar Garhwal, India.

5. Assistant Professor, Department of Pathology, Veer, Chandra, Singh, Garhwali, Governtment, Medical College and Research Institute, Sricot Srinagar Garhwal, India.

\section{NAME, ADDRESS, E-MAIL ID OF THE CORRESPONDING AUTHOR:}

Dr. Deepa Hatwal, C/O Dr. S.K. Hatwal, Health Care Centre Upper Bazar Srinagar Garhwal-246001, India.

E-mail: dhatwal@yahoo.com

\section{FINANCIAL OR OTHER COMPETING INTERESTS:} None.
Date of Online Ahead of Print: Feb 02, 2016 Date of Publishing: Apr 01, 2016 